\title{
Management and outcomes of caesarean scar pregnancy in medina maternity and children hospital
}

\author{
BahaaEldin Salama $^{1 *}$, Mohammed Mufti ${ }^{2}$, Rehab Alruwathi ${ }^{1}$, Tarig $\operatorname{Yassin}^{1}$, \\ Roqayah Tuker ${ }^{1}$, Hamza Nasser ${ }^{1}$
}

\author{
${ }^{1}$ Department of Obstetrics and Gynecology, Maternity and Children Hospital, Medina, Saudi Arabia \\ ${ }^{2}$ Hospitality Quality and Patient Safety Department, King Salman bin Abdulaziz Medical City, Medina, Saudi Arabia
}

Received: 10 June 2021

Accepted: 25 June 2021

\section{*Correspondence:}

Dr. BahaaEldin Salama,

E-mail: bebomemo1@ @otmail.com

Copyright: (c) the author(s), publisher and licensee Medip Academy. This is an open-access article distributed under the terms of the Creative Commons Attribution Non-Commercial License, which permits unrestricted non-commercial use, distribution, and reproduction in any medium, provided the original work is properly cited.

\begin{abstract}
Undergoing previous cesarean section (CS) can have the possibility for implantation of embryonic sac of any later gestation throughout its scar evolving what was known as a scar pregnancy (SP). The aim of this study to describe the diagnosis, treatment and outcomes of caesarean SP in Medina maternity and children hospital. This a case series study encompassed all patient diagnosed and managed as cesarean SP in Medina maternity and children hospital, Medina (MMCH), Saudi Arabia in the period from January 2020 to January 2021. Demographics, clinical and discharge data were attained from the previous hospital electronic records, nursing notes, anesthesia sheets, operative notes, discharge papers, and outpatient clinic documents. A total of 11 women detected by ultrasound (US) and magnetic resonance imaging (MRI) as SP. The mean age of women was $36 \pm 3.8$ years. The median number of repeated CS was 2 while the mean gestational age was 50.6 \pm 7.8 days. The interval from diagnosis to management ranged from 2 to 9 days with a median of 4 days, and the interval between start treatment and negative Beta human chorionic gonadotropin $\beta$-hCG ranged from 21 to 135 days with a median of 62 days. The mean interval from last CS until this pregnancy is $39.7 \pm 19.2$ months. Systemic methotrexate (MTX) given in a single dose for two patients while nine patients received multiple doses. Local MTX given for six cases. Bleeding as a complication occurred with two out of the eleven patients. MTX was actual treatment for SP, but bigger multicenter randomized-controlled trials involving more cases are essential to validate our conclusions.
\end{abstract}

Keywords: Cesarean, SP, Ultrasound, MTX

\section{INTRODUCTION}

Cesarean section (CS) rate rose strikingly in the last decade reaching up to $21 \%$ of deliveries. The rise was reported on 29.7 million CS annually performed among 169 countries. ${ }^{1}$ That growth advocated for a widespread of indicated "first" CS use from $12.6 \%$ to $20.6 \%$ and a decrease in vaginal births after CS from $28 \%$ to $9.2 \%$ with a repeated incident of CS nowadays of around $91 \%$. $^{2}$ Maternal adverse outcomes were greater after CS than following ordinary normal vaginal delivery. CS was claimed to be related to above average rate of ectopic pregnancy, placenta previa or accrete and ruptured uterus. Additionally, described outcomes has been linked in a direct proportionate way with the number of $\mathrm{CS}^{3} \mathrm{CS}$ extended the danger of gestational sac abnormal implantation during the consequent pregnancies on top of the cesarean scar, giving rise to what defined as SP that its danger level raised with repetitive $\mathrm{CS}{ }^{4}$ Since 2000, SP recurrence demonstrated a critical flood, reaching $6.1 \%$ of every single ectopic pregnancy in ladies with prior CS, which may be appended to both extended aggregate of CS as well as the improved detection rate of ectopic pregnancy. 5

In SP, intrusion of the sac into the myometrium happens due to dehiscence or a scar imperfection because the lower uterine segment develop fibrosis and has poor 
vascularization. ${ }^{6}$ The area of CS scar in most of complicated women is defective, especially after numerous CSs. The scar surface usually expands, and the front uterine wall can have inadequate blood supply due to fibrosis and impeded recuperating. In fact, $72 \%$ of women with SP revealed by this creator had multiple CSs. In the previously performed surgeries, double layer sutures are applied which results in modifying the principal layer continuously. A single non-reversing running suture, as normally utilized sometimes, may prompt disabled postoperative convalescing as well as formation of deformities inside the scar. ${ }^{7}$ The aim of this study is to represent the data of a tertiary care center with the recognizable proof as well as care of SP and to examine patients' difficulties identified with this uncommon sort of ectopic pregnancy. Previous report of SP occurrence was between 1:1,800 and 1:2,216 pregnancies, it comprises $6.1 \%$ of every single ectopic pregnancy with a past filled with at any rate one CS. ${ }^{8}$

Few strategies were utilized to analyze uterine SPs. Transvaginal ultrasound (TVS) assessment was the essential analytic way in a list of specific criteria. ${ }^{9}$ Those include visualization of a void uterine hole just as a void endocervical waterway, placenta detection as well as an embryonic sac, earlier of $\leq 8$ weeks a triangular sac that fills characteristically the scar, after 8 weeks the shape may be adjusted to oval, cylindrical (1-3 mm) or missing myometrium separating the sac from urinary bladder, closed hole cervix, undeveloped fetal pole \pm yolk sac \pm heart activity and powerful vascular network around CS scar zone.

Methotrexate (MTX) is a folinic acid agonist involved in the processing of DNA production. It is given in ectopic pregnancy and choriocarcinoma because it can halt the activity of highly proliferative cells. Unfavorable effects include stomatitis (5\%), diarrhea (14\%), vomiting (17\%) and nausea $(50 \%) .{ }^{19}$ MTX can be used systemically for tubal pregnancies, principally or unruptured early phase with a 90\% success rate. However, systemic MTX administration is less effective in pulsating tubal pregnancies as well as cervical or cornual ones. ${ }^{10}$ Gestational sac aspiration with the administration of methotrexate into the sac combined with systemic administration of methotrexate appears to have a better success rate and requires fewer additional interventions. In a review of 17 reported cases, $74 \%$ of the women treated with this combined method required no further interventions. $^{10}$ On the other hand, uterine artery embolization (UAE) has been used in conjunction with the administration of systemic or local methotrexate and during or after surgical removal of SP to prevent bleeding and have similar good rates of success. ${ }^{11}$

Cervical dilatation and curettage are a commonly used method of managing SP. Surgical evacuation is suitable for endogenic SP with a myometrial thickness of at least 2 $\mathrm{mm}$. However, it carries the risk of bleeding and may fail to remove all of the pregnancy sac residues in the scar tissue. It should be performed under the guidance of ultrasound to aid complete tissue removal. Various techniques to reduce bleeding during and after surgical evacuation have been reported. Most case series have reported the use of UAE with methotrexate, but other reported techniques include the use of intrauterine Foley's catheter and Shirodkar's sutures. A Shirodkar's suture applied prior to suction evacuation and tied after the procedure is an effective method of reducing bleeding following evacuation. It also avoids the risks of further intervention such as UAE and preserves future fertility.

\section{CASE SERIES}

This is a case series study that was done from January 2020 to January 2021 at maternity and children hospital $(\mathrm{MMCH})$ in Madinah, Saudi Arabia. The study was approved by the institutional review board of the hospital and all patients provided a written informed consent to participate in this study. We surveyed the electronic records of all patients admitted to obstetrics and gynecology department who were diagnosed with SP. Recruited women assented before beginning information arrangement and complete advising about potential perils up to hysterectomy. All patients were educated regarding each modality and their side effects. SP addressed through meticulous woman's history including obstetric, conceptive, clinical and careful history just as physical assessment. The data collected were fortified by the accompanying ultrasound which reported vacant uterus, CS scar approached by sac or placenta, reedy (thickness $<4 \mathrm{~mm}$ ) or missing myometrium between sac and bladder, triangular-shaped sac within the scar (as early as $\leq 8$ weeks) that move to get adjusted or once in a while oval at $>2$ months, embryonic fetal post \pm yolk sac \pm cardiovascular action, sealed and abandoned endocervical channel or high vascular example around CS scar. Afterwards, confirmation of the diagnosis and the US was done by conduction a magnetic resonance imaging (MRI).

Treatment options were offered to each patient after the diagnosis of SP. Details of the advantages and complications of each treatment was provided. Patients were monitored by pelvic examination, $\beta$-hCG test and ultrasonography in our outpatient clinic once in a week regularly until a negative $\beta$-hCG result is confirmed after the treatment.

The management included intramuscular (IM) MTX 100 mg with re-evaluation one week later by B-HCG and ultrasonography. If $\beta$-hCG did not decline or the fetal heart was still positive, we gave a second dose of IM MTX $100 \mathrm{mg}$ with another evaluation one week later. If $\beta$-hCG did not decline or fetal heart still positive, offered a local MTX $100 \mathrm{mg}$ with weekly outpatient clinic follow up.

Data included age, parity, body mass index (BMI), gestational age, interval between last cesarean delivery CD and SP, clinical presentation, general situation, interval between diagnoses and treatment, $\beta$-hCG titer, ultrasound 
and MRI finding, type of treatment and Outcome. Descriptive statistics were done using frequency and percentages for the categorical data, and using min max, median, mean, standard deviation for numeric variables.

A total of 11 participants were included in the study and the SP was distinguished by US and MRI. The mean age of the women was $36 \pm 3.8$ years. And the mean BMI was 27.7 \pm 5.4 . The mean gestational age of SP at time of diagnosis was $50.6 \pm 7.8$ days. The minimum number of previous CS was one while the maximum was five with a median of two previous CS (Table 1).

The mean interval from last CS until this pregnancy was $39.7 \pm 19.2$ months. The interval from diagnosis to the management ranged from two to nine days with a median of four days. The mean value of $\beta$-hCG level at start of treatment was $76313.8 \pm 76089.3 \mathrm{mIU} / \mathrm{mL}$, and the interval between treatment and negative $\beta$-hCG ranged from 21 to 135 days with a median of 62 days (Table 1). The general condition for all eleven patients was stable, three patients were asymptomatic while six complained of vaginal bleeding, and two cases complained of pain. There was a fetal pole in seven cases and positive fetal heart in seven cases (Table 2). Systemic MTX given in a single dose for two patients while nine patients received multiple doses. Local MTX given for six cases. Bleeding as a complication occurred with two out of the eleven patients that managed by suction curettage under US guidance (Table 3 ).

Table 1: Women's history and examination.

\begin{tabular}{|c|c|c|c|c|c|}
\hline Variables & Minimum & Median & Maximum & Mean & SD \\
\hline Age (years) & 30 & 37 & 43 & 36.0 & 3.8 \\
\hline Hight (cm) & 149 & 155 & 165 & 155.9 & 4.6 \\
\hline Weight (kg) & 50.0 & 68.2 & 89.0 & 67.4 & 13.3 \\
\hline BMI $\left(\mathrm{kg} / \mathrm{m}^{2}\right)$ & 22.2 & 27.7 & 37.0 & 27.7 & 5.4 \\
\hline Parity & 2 & 4 & 8 & 4.1 & 2.1 \\
\hline Abortion & 0 & 1 & 4 & 1.3 & 1.3 \\
\hline No. of CS & 1 & 2 & 5 & 2.5 & 1.3 \\
\hline GA (days) & 42 & 48 & 70 & 50.6 & 7.8 \\
\hline $\begin{array}{l}\text { Interval from diagnosis till } \\
\text { management (days) }\end{array}$ & 2 & 4 & 9 & 4.8 & 2.6 \\
\hline $\begin{array}{l}\text { Interval from last CS till this } \\
\text { pregnancy (months) }\end{array}$ & 12 & 38.00 & 72 & 39.7 & 19.2 \\
\hline B-HCG at start of treatment & 372 & 42992 & 261760 & 76313.8 & 76089.3 \\
\hline $\begin{array}{l}\text { Interval between treatment and - } \\
\text { ve B-HCG (days) }\end{array}$ & 21 & 62 & 135 & 63.9 & 31.3 \\
\hline
\end{tabular}

Table 2: Women's clinical characteristics.

\begin{tabular}{|llll|}
\hline Variables & & Frequency & Percent (\%) \\
\hline \multirow{5}{*}{ Parity } & 2 & 4 & 36.4 \\
& 3 & 1 & 9.1 \\
& 4 & 1 & 9.1 \\
& 5 & 3 & 27.3 \\
\hline \multirow{5}{*}{ Abortion } & 7 & 1 & 9.1 \\
& 8 & 1 & 9.1 \\
& 0 & 3 & 27.3 \\
\hline \multirow{5}{*}{ No. CS } & 1 & 5 & 45.5 \\
& 2 & 1 & 9.1 \\
\hline \multirow{3}{*}{ Complaint } & 3 & 1 & 9.1 \\
\hline \multirow{3}{*}{ General condition } & 4 & 1 & 9.1 \\
\hline & 1 & 2 & 18.2 \\
\hline & 2 & 5 & 45.5 \\
\hline & 3 & 1 & 9.1 \\
\hline & 4 & 2 & 18.2 \\
\hline & Asymptomatic & 1 & 9.1 \\
\hline & Vaginal bleeding & 3 & 27.3 \\
\cline { 2 - 5 } & Pain & 6 & 54.5 \\
\hline & Stable & 2 & 18.2 \\
\hline
\end{tabular}




\begin{tabular}{|llll|}
\hline Variables & & Frequency & Percent (\%) \\
\hline \multirow{3}{*}{$\begin{array}{l}\text { Interval from diagnosis to } \\
\text { management (days) }\end{array}$} & 2 & 1 & 9.1 \\
& 3 & 3 & 27.3 \\
\hline \multirow{2}{*}{ Fetal pole } & 4 & 4 & 36.4 \\
\hline \multirow{2}{*}{ FH } & 8 & 1 & 9.1 \\
\hline MRI & 9 & 2 & 18.2 \\
\hline & No & 4 & 36.4 \\
\hline & Yes & 7 & 63.6 \\
\hline & Negative & 4 & 36.4 \\
\hline & Positive & 7 & 63.6 \\
\hline
\end{tabular}

Table 3: Study management outcomes.

\begin{tabular}{|llll|} 
Variables & Frequency & $\begin{array}{l}\text { Percent } \\
(\%)\end{array}$ \\
\hline $\begin{array}{l}\text { Systemic } \\
\text { MTX }\end{array}$ & $\begin{array}{l}\text { Single dose } \\
\text { Multiple }\end{array}$ & 2 & 18.2 \\
\hline \multirow{2}{*}{ Local MTX } & 9 & 81.8 \\
\hline \multirow{2}{*}{ Complication } & No & 5 & 45.5 \\
\cline { 2 - 3 } & Yes & 6 & 54.5 \\
\cline { 2 - 3 } & complication & 9 & 81.8 \\
\cline { 2 - 3 } & Bleeding & 2 & 18.2 \\
\hline
\end{tabular}

\section{DISCUSSION}

SP is an uncommon ectopic pregnancy and its frequency in our center could be risen due to the upsurge of the CS rate. During study period, the rate of CS was $33.2 \%$ and the frequency of SP was $0.22 \%(11 / 5042 \mathrm{CS})$. There are two justifications of this increase, initially, as a tertiary care center, several women suffering complicated pregnancies as ectopic or SP were referred for supervision. Moreover, new advances of TVS with higher frequency probes that permitted earlier identification of such conditions. Improved detection as well as peak of the number of CS are apparently accountable for that upsurge of SP. The biological history of SP disorder is undetermined, but unprompted early scar rupture in pregnancy and bleeding, if the pregnancy could continue, with the probable hazardous maternal undesirable outcomes.

Endometrial as well as myometrial disfiguring or disturbance might lead the growing embryo into an implantation defect. In addition, inadequate decidualization could result in trophoblast invasion or adherence to the lower uterine segment. Nevertheless, the difference between a pregnancy complicated with placenta accreta to that of SP is that in the later sac it would be embedded within the myometrium being completely separated from the hollow cavity. Developing a microscopic pathway inside the fibrous CS scar was the method that mostly could describe myometrial implantation and invasion. Such pathway was mostly a direct result of a prior surgical trauma of any cavitary surgery as CS, curettage, myomectomy, removal of the placenta manually or even office hysteroscopy. ${ }^{8}$ The time interval amid trauma with subsequent pregnancy could influence implantation as many documented conditions recorded only few months following a CS hinting that partly healed the surgical wound aided the scar implantation. ${ }^{12}$

Veridiano et al illustrated a difficult case following delivery which was complicated by placenta per Creta that suffered spontaneous uterine perforation at 14 weeks' gestation in the subsequent pregnancy and was managed by emergency hysterectomy following severe hemorrhage. ${ }^{13}$ Furthermore, Herman et al was the first to utilize US to describe case of $1^{\text {st }}$ trimester sac implanted within a CS scar. ${ }^{6}$ Her pregnancy was uneventful, but the patient was delivered by emergency CS and a hysterectomy was performed due to serious blood loss that led to coagulopathy.

Firm US standards used to distinguish SP as empty cavity, empty cervical canal, anterior isthmical gestational sac and an absent healthy myometrial layer between it and the urinary bladder. ${ }^{14}$ Some physicians advocated an extra principle of high peri-trophoblastic blood flow around SP. ${ }^{15}$ Lai et al described complexity, early on the $7^{\text {th }}$ week of gestation, in finding the difference between a tubal ectopic pregnancy or in the myometrium of a prior CS. They recommended laparoscopic approach for the problem. ${ }^{16}$ On the other hand, Godin et al advised with MRI use to confirm SP. ${ }^{7}$ Its use or imaging by threedimensional color Doppler could improve the accuracy of detecting SP by measuring the flow velocity, vascular indices among the peri-trophoblastic vascular bed; yet, representations might still be like those of placenta accrete shown late in pregnancy. ${ }^{4}$ Due to the rarity of the disorder, most SPs published in form of case reports or few case series without agreement on the favorite management plan. Mostly, first trimester pregnancy termination clearly practiced preventing lethal problems. ${ }^{12}$ Management goals must be directed to implement feticide prior disturbance, losing the gestation sac and maintaining the woman's potential fertility.

MTX was primarily utilized in treating ectopic pregnancy with the following prerequisites: when gestational age $(<9$ weeks), less than $10 \mathrm{~mm}$ fetal pole size and no evidence of cardiac activity was detected with $<10,000$ IU/L serum $\beta$ hCG levels. ${ }^{17}$ Using MTX for SP management remained controversial, some used it in single systemic manner, 
while others claimed it should be in multiple doses to achieve complete resolution. ${ }^{9,18-20}$ It was primarily an accessory to hysterotomy as well as other procedures. Hypothetically, poor vascularity and fibrous tissue surrounding SP significantly limited the concentration of MTX within the lesion. Our results showed that most of the participants responded satisfactorily to systemic MTX. Rotas et al asserted sixteen women who were managed by IM MTX, 36\% with ( $\beta$-hCG $<5,000 \mathrm{mIU} / \mathrm{mL})$ resolved straightforward within few months and $36 \%$ got multiple MTX doses with oscillating leucovorin administration while two cases were complicated with bleeding which was controlled by surgical intervention. ${ }^{21}$

In our study, the median resolution time for SP in our results was 62 days that ranged from 21 to 135 days. $\mathrm{Wu}$ et al noted the $\beta$-hCG level decrease in women getting IM MTX was slow, and $16 \%$ had a $\beta$-hCG level drop by $50 \%$ following the first MTX injection. ${ }^{22}$ Yang et al also discovered that the decline time was long in SP women getting IM MTX only. ${ }^{23}$ Two of our participants (18.2\%) needed just single MTX course, while double doses were required in other nine $(81.8 \%)$ with six $(66.6 \%)$ of them requiring local MTX. Regarding the use of $\beta$-hCG level as marker for requiring supplementary therapy, Chen et al reported a $\beta$-hCG decline of $68.3 \%$ and $49.6 \%{ }^{24}$ After one week of MTX, 33,082 mIU/mL was $\beta$-hCG level after treatment in the latter case that necessitated other two extra systemic MTX courses. These data recommended that the dose and number of MTX injections mandatory should consider gestational age as well as the existence of an embryonic cardiac activity. Lastly, regardless the medical management of SP of 11 participants was effective, the assessment of MTX consequences depending on this number was insufficient for inducement of a final assumption concerning the usefulness of such protocol, especially without comparing with other existing choices. Therefore, considering CS rate rise, health workers should pay attention to the likelihood of this type of ectopic pregnancy in the woman's future pregnancies.

Limitation of our study include a small sample size despite having reviewed a large era of years. This small data does not represent the actual population. Furthermore, the nature of the paper is of descriptive due to the small number of patients included making a research on higher number on a multi-center level necessary to determine the correct factors associated with SP.

\section{CONCLUSION}

MTX was the actual treatment for SP and was effective and efficient. Other treatment modalities did not show the same when compared to MTX. However, bigger multicenter randomized-controlled trials involving more cases are essential to validate our conclusion.

Funding: No funding sources Conflict of interest: None declared

Ethical approval: Not required

\section{REFERENCES}

1. Boerma T, Ronsmans C, Melesse DY. Global epidemiology of use of and disparities in caesarean sections. Lancet. 2018;392(10155):1341-8.

2. Betrán AP, Temmerman M, Kingdon C. Interventions to reduce unnecessary caesarean sections in healthy women and babies. Lancet. 2018;392(10155):135868.

3. Sandall J, Tribe RM, Avery L. Short-term and longterm effects of caesarean section on the health of women and children. Lancet. 2018;392(10155):134957.

4. Timor-Tritsch IE, Monteagudo A. Unforeseen consequences of the increasing rate of cesarean deliveries: early placenta accreta and cesarean scar pregnancy. A review. Am j obstetr gynecol. 2012;207(1):14-29.

5. Vial Y, Petignat P, Hohlfeld P. Pregnancy in a cesarean scar. Ultrasound in obstetrics and gynecology. J Int Society Ultrasound Obstetr Gynecol. 2000;16(6):592-3.

6. Herman A, Weinraub Z, Avrech O, Maymon R, RonEl R, Bukovsky Y. Follow up and outcome of isthmic pregnancy located in a previous caesarean section scar. Bri J obstetr gynaecol. 1995;102(10):839-41.

7. Godin PA, Bassil S, Donnez J. An ectopic pregnancy developing in a previous caesarian section scar. Fertility and sterility. 1997;67(2):398-400.

8. Seow KM, Hwang JL, Tsai YL, Huang LW, Lin YH, Hsieh BC. Subsequent pregnancy outcome after conservative treatment of a previous cesarean scar pregnancy. Acta obstetric gynecol Scandinavica. 2004;83(12):1167-72.

9. Shufaro Y, Nadjari M. Implantation of a gestational sac in a cesarean section scar. Fertility sterility. 2001;75(6):1217.

10. Sadeghi H, Rutherford T, Rackow BW. Cesarean scar ectopic pregnancy: case series and review of the literature. Am J perinatol. 2010;27(2):111-20.

11. Lian F, Wang Y, Chen W. Uterine artery embolization combined with local methotrexate and systemic methotrexate for treatment of cesarean scar pregnancy with different ultrasonographic pattern. Cardiovascular interventional radiol. 2012;35(2):28691.

12. Maymon R, Halperin R, Mendlovic S. Ectopic pregnancies in Caesarean section scars: the 8 year experience of one medical centre. Human reproduction. 2004;19(2):278-84.

13. Veridiano NP, Lopes J, Ohm HK, Tancer ML. Placenta percreta as a cause of uterine perforation during abortion. A case report. J reproductive med. 1986;31(11):1049-50.

14. Fylstra DL. Ectopic pregnancy within a cesarean scar: a review. Obstetric gynecol survey. 2002;57(8):53743.

15. Seow KM, Hwang JL, Tsai YL. Ultrasound diagnosis of a pregnancy in a Cesarean section scar. Ultrasound 
in obstetrics and gynecology. J Int Society Ultrasound Obstet Gynecol. 2001;18(5):547-9.

16. Lai YM, Lee JD, Lee CL, Chen TC, Soong YK. An ectopic pregnancy embedded in the myometrium of a previous cesarean section scar. Acta obstetric gynecol Scandinavica. 1995;74(7):573-6.

17. Hung TH, Shau WY, Hsieh TT, Hsu JJ, Soong YK, Jeng CJ. Prognostic factors for an unsatisfactory primary methotrexate treatment of cervical pregnancy: a quantitative review. Human reproduction. 1998;13(9):2636-42.

18. Ayoubi JM, Fanchin R, Meddoun M, Fernandez H, Pons JC. Conservative treatment of complicated cesarean scar pregnancy. Acta obstetric gynecol Scandinavica. 2001;80(5):469-70.

19. Ravhon A, Ben-Chetrit A, Rabinowitz R, Neuman M, Beller U. Successful methotrexate treatment of a viable pregnancy within a thin uterine scar. Bri $\mathrm{j}$ obstetr gynaecol. 1997;104(5):628-9.

20. Nawroth F, Foth D, Wilhelm L, Schmidt T, Warm M, Römer T. Conservative treatment of ectopic pregnancy in a cesarean section scar with methotrexate: a case report. Eur $\mathrm{j}$ obstetr gynecol reprod biol. 2001;99(1):135-7.
21. Rotas MA, Haberman S, Levgur M. Cesarean scar ectopic pregnancies: etiology, diagnosis, and management. Obstetric gynecol. 2006;107(6):137381.

22. Wu X, Zhang $X$, Zhu J, Di W. Caesarean scar pregnancy: comparative efficacy and safety of treatment by uterine artery chemoembolization and systemic methotrexate injection. Eur J obstetr gynecol reprod biol, 2012;161(1):75-9.

23. Yang XY, Yu H, Li KM, Chu YX, Zheng A. Uterine artery embolisation combined with local methotrexate for treatment of caesarean scar pregnancy. Int J obstetr gynaecol. 2010;117(8):990-96.

24. Chen F-Y, Torng P-L, Huang S-C, Chow S-N. Ectopic Pregnancy Within a Cesarean Section Scar: Report of Two Cases. Taiwanese J Obstetr Gynecol. 2004;43(1):38-41.

Cite this article as: Salama B, Mufti M, Alruwathi R, Yassin T, Tuker R, Nasser H. Management and outcomes of caesarean scar pregnancy in medina maternity and children hospital. Int J Reprod Contracept Obstet Gynecol 2021;10:2848-53. 